\title{
KONTROVERSI MUSHAF UTSMANI
}

\author{
Vlil Hidayah \\ Mahasiswa Pascasarjana UIN Maulana Malik Ibrahim Malang \\ Email: permata_ulya@yahoo.co.id
}

\begin{abstract}
The Quran has sailed a long history, beginning with the receipt of the divinity message of Muhammad which was conveyed to Muslim generations by recording it through memorization and writing. Initially, in teaching al Quran Muhammad used tribal dialect if necessary. Yet, after the Prophet passed away, the various dialect of the letters in the Quran lead to confusion and dispute in society. Therefore, when Uthman became caliph, he ordered that all manuscripts be destroyed, and formed a team of Mushaf bookkeeping led by Zaid bin Thabit. The manuscripts verified by Uthman were sent to all parts of the Islamic State. However, Ibnu Mas'ud, one of the companions who wrote manuscripts during prophet's era, rejected the order. He refused reading Zaid's mushaf because during Zaid's childhood Ibnu Mas'ud had been memorizing more than seventy surahs uttered by the Prophet.
\end{abstract}

Al Quran telah mengarungi sejarah panjang, diawali dengan penerimaan pesan ketuhanan oleh Muhammad yang kemudian disampaikan kepada generasi Islam dengan merekamnya melalui menghafal dan menulis. Awalnya dalam mengajarkan al Quran nabi Muhammad menggunakan dialek sesuai kesukuan jika dirasa perlu. Namun setelah Rasulullah wafat terdapat banyak dialek yang menyebabkan huruf al Quran mulai menampakkan kerancuan dan perselisihan dalam masyarakat. Maka pada masa khalifah Utsman, diperintahkan agar semua mushaf dimusnahkan dan dibentuk tim pembukuan mushaf al Quran yang dipimpin oleh Zaid bin Tsabit. Naskah yang sudah di verifikasi Utsman dikirimkan ke seluruh wilayah negara Islam. Namun, Ibnu Mas'ud salah satu sahabat yang telah menulis mushaf sejak masa nabi menolak membakar mushafnya. Dia tidak mau membaca qiraat Zaid, karena semasa Zaid masih kecil Ibnu Mas'ud telah menghafal lebih dari tujuh puluh surah langsung dari lisan Rasulullah.

Keywords: controversy, manuscripts of Utsman 


\section{Pendahuluan}

Al Quran yang diturunkan dalam rentang dua puluh tiga tahun secara berangsur-angsur telah memenuhi tuntunan situasi dan lingkungan yang ada pada masa itu. Dalam memelihara ingatan al Quran nabi Muhammad, Jibril berkunjung kepadanya setiap tahun, hanya pada tahun kematiannya Jibril datang dua kali dan membaca seluruh isi kandungan al Quran secara bergantian. Hal tersebut dapat dilihat dalam haditst yang diriwayatkan Fatimah bahwa:

"Nabi Muhammad memberitahuku secara rahasia, malaikat Jibril hadir membacakan al Quran padaku dan saya membacakannya sekali setahun. Hanya tahun ini ia membacakan seluruh seluruh isi kandungan al Quran selama dua kali.saya tidak berpikir lainkecuali rasanya, kematian sudah mendekat" (Shahih Bukhari, tt: 7).

Kemudian juga Ibnu 'Abbas melaporkan bahwa nabi Muhammad berjumpa dengan malaikat Jibril setiap malam selama bulan Ramdhan hingga akhir bulan, masing-masing membaca al Quran silih berganti (Shahih Bukhari, tt: 7). Tugas nabi Muhammad terhadap wahyu sangat instrumental, yaitu sebagai pengawas ketepatan kompilasi, memberi keterangan yang diperlukan, memacu masyarakat luas dalam pengenalan dan penyebarluasan, dan sebagai mahaguru para sehabat. (Al A'zami, 2005: 56).

Sejak pewahyuan hingga kini al Quran telah mengarungi sejarah panjang selama empat belas abad lebih. Diawali dengan penerimaan pesan ketuhanan oleh Muhammad yang kemudian disampaikan kepada generasi Islam dengan merekamnya dengan cara menghafal maupun menulis. Dalam mengajarkan al Quran nabi Muhammad menggunakan dialek sesuai kesukuan jika dirasa perlu, karena masyarakat Makkah mayoritas memiliki latar belakang budaya yang beragam. Sebagai contoh kata qultu orang Mesir mengungkapkan dengan ult, diganti dengan $u$ dari kosakata $q$. orang Yaman mengatakan dengan ungkapan ghultu kendati dalam menulis kata-kata semua orang arab akan mengatakan secara identik (al A'zami, 2005: 67).

Keragaman dialek mulai sirna setibanya Nabi di Madinah, karena dengan meluasnya ekspansi Islam melintasi belahan wilayah arab lain dengan suku bangsa dan dialek baru. Dikutib dalam kitab Shahinya Muslim hadits berikut: "Ubay melapokan ketika Nabi berada didekat lokasi banu Ghifar Malaikat Jibril datang da berkata, "Allah telah menyuruh kamu untuk membaca al Quran kepada kaummu dalam satu dialek", lalu Nabi berkata, "Saya mohon ampunan Allah kaumku tidak mampu untuk itu" lalu Jibril datang lagi untuk kedua kalinya dan berkata, "Allah telah menyuruhmu agar membaca al 
Quran pada kaummu dalam dua dialek, "Nabi Muhammad lalu menjawab "saya mohon ampunan Allah kaumku tidak dapat melakukannya" Jibril datang lagi untuk ketiga kalinya dan berkata, "Allah telah menyuruhmu agar membaca al Quran pada kaummu dalam tiga dialek, " dan Nabi berkata "saya mohon ampunan Allah kaumku tidak dapat melakukannya" lalu Jibril datang keempat kalinya dan menyatakan "Allah telah mengizinkanmu membaca al Quran pada kaummu dalam tujuh dialek, dan dalam dialek apa saja mereka gunakan sah-sah saja” (Muslim, tt: 298).

\section{Kodifikasi Al Quran}

Setelah hijrah ke Madinah, nabi Muhammad memerintahkan sekretarsinya untuk menuliskan wahyu, diantara para sahabat yang menuliskan wahyu adalah empat khalifah pertama, Mu'awiyah, Ubay Ibnu Ka'b, Zaid bin Stabit, Ibnu Mas'ud, abu Musa Al Asy'ari dan lain-lain, bahkan disebutkan ada 34 sahabat nabi yang di tugaskan dalam mencatat wahyu (Adnan, 2001: 132). Praktik yang berlaku dikalangan para sahabat tentang penulisan al Quran menyebabkan Nabi Muhammad melarang orang-orang menulis sesuatu darinya kecuali al Quran, apabila sampai terjadi maka ia harus menghapusnya. Beliau ingin agar al Quran dan hadits tidak tercampur (al A'zami, 2005: 73). Dalam sebuah riwayat juga di ceritakan bahwa apabila wahyu turun Nabi memanggil memanggil sekretarisnya, kemudian bersabda "letakkan ayat ini dalam surat yang menyebutkan begini”. Penggabungan unit-unit wahyu atau penempatannya kedalam surat-surat al Quran atas petunjuk nabi ini di sebut tawqifi (Adnan, 2001: 132). Demikianlah susunan unit dalam al Quran disusun sendiri oleh nabi dan diikuti para sahabat, itulah sebabnya ketika dibuka kumpulan al Quran para sahabat ditemukan perbedaan yang cukup signifikan dalam susunan surat bukan susunan ayat. Para ulama' sepakat bahwa mengikuti susunan surat dalam al Quran bukan suatu kemestian, baik dalam bacaan shalat, hafalan, belajar maupun bacaan (al A'zami, 2005: 77).

\section{Mushaf Pra Utsman}

Setelah Rasulullah wafat pada masa khalifah Abu Bakar terjadi perang Yamamah yang banyak menelan para penghafal al Quran dan berakibat sebagian al Quran akan musnah. Maka dibukukannya al Quran atas usul Umar, meskipun pada masa Nabi tidak pernah dilakukan Umar meyakinkan Abu Bakar bahwa hal ini merupakan demi kebaikan. Kemudian Abu Bakar berkata kepada Zaid "sesungguhnya kamu adalah pemuda yang cekatan dan aku tidak 
meragukan kemampuanmu, kamu dulu adalah penulis wahyu Rasulullah, kini teruskanlah dan carilah seluruh al Quran agar dapat dirangkum seluruhnya”. Kemudian Zaid menjawab "demi Allah, jika sekiranya mereka meminta kami memindahkan sebuah gunung raksasa, hal itu akan tersa lebih ringan daripada apa yang mereka perintahkan sekarang" (al Bukhari, tt: 831).

Dalam mengumpulkan ayat-ayat al Quran Zaid tidak hanya mengambil dari sumber tulisan baik itu diatas kertas, kulit, papan, kayu dan daun-daun, melainkan merujuk pada hafalan-hafalan orang lain. Zaid pada dasarnya mencari ayat tertulis dari berbagai sumber yang masih berceceran dan untuk dicocokkan dengan apa yang telah dihafal para huffadz. Ayat-ayat yang dikumpulkan melibatkan partisipasi banyak orang, sebagaimana Ibnu Hajar memberikan perhatian secara khusus terhadap keterangan yang diberikan Zaid, "saya dapati dua ayat terakhir dalam surat al Baro'ah hafalan ada pada Abu Khuzaima al Ansari (serta saksi-saksi yang menjadi kemestiannya) yang diperkuat dengan hafalan Zaid dan beberapa huffadz lainnya, " (al A'zami, 2005: 90), ini membuktikan bahwa tulisan yang ada pada Zaid serta hafalannya dianggap tidak mencukupi. maka setelah tugas terselesaikan kompilasi al Quran disimpan dalam arsip kenegaraan dibawah pengawasan Abu Bakar. Kompilasi ini disebut dengan Shuhuf (mufrod dari Mushaf).

Riwayat lain menyebutkan Ali bin Abi Thalib merupakan orang yang pertama yang mengumpulkan al Quran setelah wafatnya Nabi, Ali mengurung diri di rumahnya dan bersumpah tidak akan keluar rumah sebelum mengumpulkan bahan-bahan al Quran dalam sebuah mushaf (Adnan, 2005: 134). Hal ini menimbulkan berita tidak keluarnya Ali karena tidak ingin bersumpah setia (bai'ah) kepada khalifah yang baru terpilih.

Pada saat Utsman menjadi khalifah, ia memerintahkan agar semua mushaf dimusnahkan, dan Ali turut menyertakan naskahnya. Hal ini diduga jika mushaf Ali bisa selamat maka akan menjadikan mushaf standar bagi kaum Syi'ah. Mushaf Ali bin Abi Thalib memiliki ciri khusus yang tidak dimiliki oleh mushaf lainnya. Karakter khusus mushaf Ali adalah:

a. Ayat dan surat tersusun rapi sesuai dengan urutan turunnya, maka ayatayat makkiyah diletakkan sebelum ayat-ayat madaniyah, ayat-ayat yang turun masa awal diletakkan lebih dahulu dari pada ayat-ayat yang turun belakangan.

b. Bacaan yang tercantum dalam mushaf ini lebih mendekati keaslian sehingga lebih sesuai dengan bacaan Rasul

c. Ada catatan tanzil dan takwil di tepi mushaf yang menjelaskan situasi dan 
kondisi serta latar belakang ayat-ayat al Quran diturunkan. Penjelasan ini sangat berguna dalam menggali maksud ayat-ayat al Quran diturunkan serta menyingkap makna-makna ayat yang masih samar (al Suyuthi, tt: 157).

\section{Mushaf Masa Utsman}

Pada masa pemerintahan khalifah Utsman pasukan tempur di medan jihad sampai ke Azerbaijan dan Armenia, mereka juga membawa al Quran untuk diajarkan dalam dialek masing-masing, karena dirasa sulit meninggalkan dialeknya secara sepontan. Akan tetapi sebagai akibatnya adanya perbedaan dalam menyebutkan huruf al Quran mulai menampakkan kerancuan dan perselisihan dalam masyarakat. Hudhaifa bin al Yaman melapor pada Utsman setelah melihat perbedaan di kalangan ummat Islam dibeberapa wilayah dalam membaca al Quran. Dalam peperangan di Armenia, umat Islam bertengkar karena dalam salat ada yang membaca Wa atimmul hajja wal 'umrata lillah dan ada yang membaca Wa atimmul hajja wal 'umrata lil bait, hal ini dihawatirkan akan menimbulan perselisihan di antara kaum muslim. Maka kemudian Utsman mengirimkan surat kepada Hafsah dengan pesan "kirimkan suhuf kepada kami agar kami dapat membuat naskah yang sempurna dan kemudian suhuf akan kukembalikan kepadamu" (al A'zami, 2005: 99).

Kemudian beliau memeberitahukan kepada tiga orang Quraisy apabila tidak sependapat dengan Zaid perihal mengenai al Quran tulislah dalam dialek Quraisy sebagaimana al Quran telah diturunkan dalam logat mereka. Ketika Utsman memutuskan untuk mengumpulkan al Quran, beliau membentuk panitia yang terdiri dari dua belas orang terdiri dari suku Quraisy dan suku Anshar, identitas dua belas orang ini bisa dilacak melalui beberapa sumber. Al A'zami menyatakan diantaranya adalah Zaid bin Stabit, Sa'id bin al Asm, Nafi' bin Zubair, Ubayy bin Ka'b, 'Abdullah bin az-Zubair, 'Abdur Rahman bin Hisyam, Khatir bin Aflah, Anas bin Malik, 'Abdullah bin Abbas, Malik bin Abi 'Amir, 'Abdullah bin Umar, 'Abdullah bin Amir bin al'As (al Baihaqi. tt: 358).

Kecakapan Zaid dalam memimpin tugas yang telah diperintahkan Utsman begitu profesional sebagaimana tugasnya terlebih dahulu. Ketika Utsman hendak membuat salinan naskah resmi, dia meminta agar Aisyah mengirimkan kepadanya suhuf yang dibacakan oleh Nabi Muhammad yang disimpan dirumahnya, kemudian menyuruh Zaid bin Tsabit membetulkan sebagaimana mestinya (al A'zami, 2005: 102). Setelah naskah diselesaikan Utsman kembali membandingkan dengan suhuf yang ada pada Hafsah guna 
melakukan verivikasi.

Naskah yang sudah di verifikasi oleh Utsman dikirimkannya duplikat naskah mushaf tersebut untuk disebarluaskan ke seluruh wilayah Negara Islam dan disebutkan naskah itu dikirim ke Kufah, Basrah, Suriah, Makkah, Yaman dan Bahrain sedangkan satunya disimpan di Madinah. Setelah naskah diresmikan maka tidak ada manuskrip lainnya untuk diabadikan. Utsman mmerintahkan agar semua Mushaf milik pribadi yang berbeda dengan Mushaf miliknya harus dibakar, jika gagal untuk menghapuskan Mushaf-Mushaf itu akan memicu munculnya perselisihan kembali, dalam riwayat lain ada yang menyebutkan tulisan trsebut dirobek-robek dan ada pula yang mengatakan hanya dihapus tintanya (al A'zami, 2005: 108). Beberapa orang memilih untuk membandingkan Mushaf mereka dengan Mushaf Utsman dan saat terlihat adanya perbedaan mereka mengubahnya (al A'zami, 2005: 109).

Pernyataan dari Abdul A'la ketika masuk ke rumah Abu Musa al Asy'ari ditemui sedang bersama Hudaifah bin Yaman dan Abdullah bin Mas'ud mereka sedang berkumpul mengelilingi Mushaf yang dikirimkan Utsman dengan membawa Mushaf mereka masing-masing secara teratur untuk membetulkannya berdasarkan Mushaf Utsmani, Abu Musa berkata kepada mereka, "apa saja yang kamu dapat dalam Mushaf saya dan terdapat pada ushaf Utsmani (tambahan), maka jangan di buang, jika anda menjumpai ada yang tertinggal dari Mushaf saya, maka tuliskanlah" (Dawud, 1982: 35). Adapun Ciri-ciri mushaf Utsman adalah:

a. Susunannya seperti yang banyak beredar saat ini, hanya ada perbedaan sedikit dengan beberapa mushaf sahabat dalam susunan atau urutan surat. Misalnya jika mushaf sahabat lainnya meletakkan Surat Yunus masuk dalam tujuh surat besar dan di urutuan ke-7, maka mushaf Utsmani menggolongkannya ke dalam kelompok Ma'in. Ini menunjukkan bahwa susunan alQuran yang ada saat ini adalah hasil ijtihad sahabat, dan bukan tauqifi dari Allah SWT atau Nabi SAW (Salih, 1975: 195).

b. Tanda baca seperti titik dan harakat tidak ada, sehingga masih sulit membedakan huruf dan tata bahasa (i'rab dan wazan kalimat). Beberapa contoh kesalahfahaman dalam bacaan kalimat misalnya:

Sulit dibedakan "yablu, nablu, tablu, tatlu, yatlu, natlu"

Sulit membedakan ya'lamuhu, ta'lamuhu, na'lamuhu, bi'ilmihi', dll.

Maka ayat "litakuuna liman khalfaka ayatan" sering dibaca "litakuuna liman khalaqaka ayatan".

"Nunsyizuha, Nunsyiruha, Tunsyiruha" (al Baqarah: 259)

"Yuallimuhu, nu'allimuhu, ya'lamuhu, na'lamuhu" (Ali 'Imran: 48) 
"Nunajjika" atau : Nunahhika" (Yunus: 92)
"Lanubawwiannahum" atau "lanubawwiyannahum" (al A'zami, 2005: 173).

c. Tata tulisan tidak konsisten sebagai akibat kesalahan dalam imla' dan الكتب , الرحمان kadang ditulis dengan الكتاب :

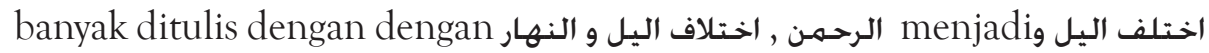
النهار. (al A'zami, 2005: 111) dan (Adnan, 2001: 207).

Berbagai riwayat menyatakan Utsman memerintahkan komisinya untuk menempatkan surat-surat panjang secara berurutan. Jumlah surat yang kesemuanya 114 dirujuk dengan nama-nama yang beragam contohnya nama surat pertama al fatihah, ummul kitab, fatihul kitab, lebih lengkap, tidak jarang terdapat dua atau lebih untuk satu surat, namun pada sekitar abad ke-8 nama-nama surat itu telah memasyarakat (Adnan, 2001: 212).

Jadi jelas nama surat bukan bagian dari al Quran tetapi hasil ijtihad dari komisi Utsman. Dari ke-114 surat tersebut pada masa awal diklasifikasikan dalam empat kategori utama: al thiwal (tujuh surat terpanjang), al mi'un (surat yang terdiri seratus ayat atau lebih), al mastani (surat yang kurang dari seratus ayat), dan al mufashol (surat pendek), pada perkembangan selanjutnya kaum muslimin membaginya kedalam 30 bagian (Adnan, 2001: 125).

\section{Penolakan Ibnu Mas'ud}

Abdullah Ibnu Mas'ud berasal dari strata bawah masyarakat makkah yang masuk Islam saat pertamakali Islam di dakwahkan. Ia mengikuti Nabi sebagai pebantu pribadinya saat hijrah ke Abisinia. Ibnu Hisyam dalam bukunya "Life of Muhammad" melaporkan bahwa ia adalah Muslim pertama yang membacakan bagian dari ayat-ayat al Quran secara lantang dan terbuka kepada kaum Quraisy yang melemparinya dengan batu. Dia pula yang menjadikan dirinya algojo bagi pemenggalan kepala Abu Jahl demi Nabinya. Huzaifah bin al Yaman (sahabat dari kaum Ansar) sampai memberi testimony tentang akhlak dan perilakunya yang mirip Rasulullah yang diteladaninya. Selain dari itu, ia juga yang paling dipuji dalam hal pengajian dan otoritas keilmuan al Quran oleh Nabi sendiri: "Belajarlah mengaji Quran dari 4 orang: dari Abdullah bin Mas'ud, Salim (budak merdeka dari Abu Hudhaifah), Mu'adh bin Jabal, dan Ubay bin Ka'b" (al Bukhari, tt: 96-97).

Pada saat pemerintahan Umar, Ibnu Mas'ud dikirim ke kufah sebagai qadhi pembendaharaan Negara, namun pada masa Utsman ia di pecat karena 
dianggap tidak sukses dan kembali ke Madinah (Adnan, 2001: 169). Dalam penyeragaman mushaf yang dibentuk oleh Utsman, Ibnu Mas'ud yang merasa lebih banyak mengetahui tentang seluk beluk al Quran jelas tidak setuju dengan penyeragaman, apalagi ketika Zaid ibn Tsabit yang ditunjuk sebagai ketua komite. Ibnu Mas'ud menilai penyeragaman hanya akan mematikan keleluasaan dan kemudahan umat dalam membaca dan memahami al Quran yang telah dibolehkan oleh Nabi SAW sejak masa awal. Diperkirakan ia mengawali pengumpulan mushafnya sejak Nabi hidup dan berlanjut sepeninggal Nabi. Setelah ditempatkan di Kufah, mushafnya berpengaruh kuat dan memiliki otoritas di kalangan penduduk Kufah. Dikabarkan ia menolak menyerahkan mushafnya kepada khalifah Utsman, dikarenakan mushaf resmi disusun oleh Zaid, sedangkan Ibnu Mas'ud adalah senior qurra'. Salah satu argument dari kaum orientalis adalah bahwa Abdullah Ibnu Mas'ud menolak membakar Mushafnya dan mengatakan "bagaimana mungkin kalian menyuruhku membaca qiraat Zaid, ketika Zaid masih kecil dan bermain dengan kawan sebayanya saya telah menghafal lebih dari tujuh puluh surah langsung dari lisan Rasulullah.

Sejumlah muslim menerima mushaf Utsmani yang baru, tetapi sebagian besar penduduk tetap berpegang mushaf Ubay di Syiria dan mushaf Ibnu Mas'ud di Kufah. Sedemikian kuatnya pengaruh mushaf ini, hingga sejumlah mushaf sekunder, seperti mushaf 'Al qamah, al Rabi' bin al Khutsaim, al Aswad, al A'masy, mendasarkan teksnya atas Ibnu Mas'ud. Karakteristik yang mencolok dari mushaf ini adalah ketiadaan tiga surat pendek, al Fatihah, al Falaq, dan an Nas. Ibnu Nadim menyatakan ia melihat sebuah manuskrip mushaf Ibnu Mas'ud yang berusia 200 tahun bertuliskan surat al Fatihah di dalamnya, tetapi ia menambahkan dari sejumlah manuskrip Ibnu Mas'ud tidak ada yang bersesuaian antara satu dengan yang lainnya (al A'zami, 2005: 219).

Ibnu al Nadim mendaftar jumlah seluruh surat yang ada di mushaf Ibnu Mas'ud 110, tetapi yang ditulis dalam al Fihrist. Al Fihrist merupakan suatu karya bibliografi Islam yang menggambarkan perkembangan Islam berdasarkan kajian terhadap literatur yang terbit di dunia Muslim. sebuah karya bibliografi terbesar sepanjang masa yang ditulis Ibnu al Nadim pada abad ke-10 M. Al Fihrist pertama kali dipublikasikan pada 938 M. Al Fihrist telah membantu para ilmuwan dan sejarawan tentang ilmu-ilmu Islam serta karya-karya klasik berbahasa Arab hanya 105 surat. Selain 3 surat di atas, surat al Hijr, al Kahfi, Toha, al Naml, al Syura, al Zalzalah tidak disebutkan. Tetapi keenam surat 
yang akhir ini ditemukan dalam al Itqan. Di kalangan Sunni maupun Syi'ah, tradisional maupun kontemporer, sarjana maupun ulama, kitab al Itqan fi 'Ulum al Quran merupakan rujukan utama bagi para pengkaji al Quran dan disiplin ilmu-ilmu turunannya. Meskipun banyak buku tentang kajian al Quran, al Itqan tetap memiliki daya pikat khas yang mampu menghadirkan al Quran sebagai kitab suci yang mengandung samudra ilmu yang amat luas dan dalam (al Suyuthi, tt: 849), pengarang kitab al Itqan, merupakan ulama terkemuka pada zamannya. Penulis prolifik dalam berbagai disiplin ilmu tafsir, hadits, fiqih, linguistik, semantik, sejarah, sastra, dan tasawuf ini telah banyak mewarnai khazanah pemikiran Islam sejak abad pertengahan hingga abad modern, justru yang tidak ada dalam daftar al Suyuthi adalah surat Qaf, al Hadid, al Haqqah, dan 3 surat yang disebutkan di atas, sehingga menurut daftar al Suyuthi berjumlah 108 surat. Diduga kuat perbedaan laporan ini kesalahan penulisan belaka, karena keenam surat yang hilang dalam al Fihrist ditemukan dalam al Itqan, begitu juga dengan 3 surat yang tidak ada dalam al Itqan.

Selain itu kata-kata dalam ayatnya banyak berbeda dengan kebanyakan catatan sahabat lain, karena menurutnya kata-kata al Quran boleh diganti dengan sinonimnya, baik untuk lebih menjelaskan maknanya, atau agar mudah dibaca orang suku tertentu. Beberapa perbedaan mushafnya dengan mushaf resmi seperti dicontohkan, tathawwa'a khairan disisipkan huruf ba, sehingga dibaca tathawwa'a bikhairin, peghilangan kata 'an dalam yas'alunaka 'ani-l anfal menjadi yas'alunaka-l anfal, penggantian kata dengan kata lain yang bermakna sama seperti aydiyahuma dibaca aymanuhuma, dan ada yang bermakna lain, seperti ilyasa dan ilyasin (QS al Shaffat: 123-130) diganti dengan idrisa dan idrasin, penyisipan beberapa kata seperti wa ajwajuhu ummahatuhum disisipi wa huwa abun lahum, atau satu kata seperti min qabli hadza disisipkan al Qurani, perbedaan kata dalam kerangka konsonan teks yang sama sehingga dibaca dengan kalimat yang beda, seperti baqiyyatin (QS Hud: 116), huruf $b a^{\prime}$ dibaca $t a^{\prime}$, sehingga dibaca taqiyyatin, penambahan beberapa ayat ekstra, penghilangan satu frase kalimat yang tidak merubah maknanya, penghilangan ayat keenam QS. Al Insyirah dikarenakan pengulangan dari ayat 5. Sebagian kata dalam ayat diganti dengan kata lain dengan maksud agar lebih jelas. Misalnya kata shauman (puasa) dalam surat Maryam ayat 26 diganti shamtan (diam), karena maksud ayat tersebut adalah nazar berpuasa untuk diam tidak berkata-kata (al Bukhari, tt: 225, Ibnu Katsir, tt: 261, al Suyuthi, tt: 58, Ibnu Qutaibah, tt: 48-49). 
Abu Hayyan an Nahwi mengemukakan kebanyakan riwayat yang berkaitan dengan ibn Mas'ud mengambil sumber dari kelompok syi'ah (al A'zami, 2005: 218).

Sebagian pendapat mengatakan, fatwa Ibnu Mas'ud tidak menerima surat al Fatihah dan surat mu'awidatain sebenarnya telah ditolak oleh beberapa ulama' Islam, diantaranya Imam Ibnu Hazm Ulama besar dari Andalusia, karena terbukti dalam qiraat Imam Ashim mushaf dari Ibnu Mas'ud terdapat al Mu'awidatain dan al Fatihah (Diraz, 1993: 27).

Keraguan akan pewahyuan surat al Fatihah ini sungguh didukung oleh segudang fakta historis, antara lain menyangkut hal-hal berikut ini:

1. Surat al Fatihah ini tidak mempunyai pijakan asalusul dan sebab-musabab pewahyuannya, ia yang sekalipun dianggap surat paling terhormat, namun muncul begitu saja tanpa silsilah

2. Kosong kronologi, tidak diketahui kapan ia diturunkan dan dimana. Bahkan tak ada indikasi ia diturunkan setelah ayat atau surat apa.

3. Tidak memiliki legitimasi ilahi dalam tata-letaknya sebagai Ummul Kitab, al Kafiyah, al Asas dan sebagai surat pertama, sebab bukan Muhammad yang menetapkannya disana.

4. Kosong dari saksi-mata, sebab siapakah yang sudah membacanya sebagai wahyu sebelum hijrah. Al Fatihah hanya diketahui muncul ketika liturgi Islam dibakukan dalam tradisi shalat setelah mikraj dan hijrah ke Madinah.

Al A'mash, Abu Ishaq, Abdur Rahman bin Yazid mengatakan Ibnu Mas, ud menghapus surat Mu'awidatain dari Mushafnya dan mengatakan bahwa keduanya bukan bagian dari al Quran, (al A'zami, 2001: 221). Ibnu 'Uyaynah dan Asim Zirr menambahkan bahwa ia tidak menolak kedua surat itu melainkan kedua surat itu sebagai doa Nabi Muhammad untuk cucunya Hasan dan Husain sehungga ia tetap tidak merubah pendiriannya.

\section{Respon Intelektual Muslim}

Terjadi perbedaan dalam bacaan dan penulisan al Quran (perbedaan mushaf) telah mendapat perhatian dan dijawab oleh kalangan ilmuwan muslim dengan berbagai pendekatan.

1. Pendekatan tradisionalis melihat perbedaan dalam bacaan dan tulisan al Quran sebagai ketentuan dari Nabi atau bahkan langsung dari Allah SWT. Dalam pendekatan ta'abbudiy ini ada anggapan kuat bahwa berbagai tulisan al Quran yang menyimpang dari kaidah standar bahasa Arab memang 
berasal dari Nabi, sebagaimana peletakkan urutan serta nama ayat dan surat juga berasal dari Beliau. Perspektif tradisionalis ini memang lebih banyak mengangkat aspek realitas namun cenderung tidak kritis karena kurang menggali latar belakang perbedaan dalam penulisan atau pembacaan al Quran. Kelemahan lain dari pendekatan ini adalah kurang mengungkap nilai-nilai positif dan pemanfaatan perbedaan untuk menggali kekayaan dan kedalaman pemikiran Islam ke depan. Kata ditulis menjadi الصلاة الزكاة dan zakat dalam mushaf Utsmani misalnya ditulis dengan huruf waw, padahal kaidah standar menggunakan huruf alif. Taufiq (Adnan, 2001: 309). Namun ada yang meyakini penyimpangan seperti ini memang berasal dari Nabi SAW sehingga harus diikuti apa adanya. Bagi kalangan ini, dispensasi kebolehan berbeda dalam bacaan dan penulisan al Quran hanya bersifat darurat, untuk sementara pada situasi saat itu saja, dan tidak berlaku lagi untuk masa dan orang-orang sesudahnya. Asumsi seperti ini ternyata banyak dipertahankan oleh banyak ulama tafsir atau penulis kitab-kitab 'ulum al Quran. Pendekatan dan pola pikir seperti ini tentu cenderung bersifat taqlid sehingga kurang mengembangkan inovasi dan kreatifitas umat Islam. Pandangan tidak jauh berbeda dikemukakan oleh Said Sukamta yang menyatakan bahwa kebolehan berbeda dalam bacaan atau tulisan al Quran pada masa Nabi memang ada namun kebolehan itu bersifat terbatas dan darurat. Untuk saat ini tidak boleh ada perbedaasn lagi (Said, 2008: 45).

2. Pendekatan kritis memandang perbedaan dan penyimpangan dalam bacaan atau penulisan al Quran bukan sebagai hal yang alami, tetapi justru mencurigai memang ada unsur-unsur kesalahan di dalamnya. Kesalahan ini sangat mungkin dilakukan oleh tim penulis mushaf bentukan khalifah Utsman yang diketuai oleh Zaid Ibnu Tsabit atau juga dilakukan oleh individu sahabat tertentu ketika menulis mushaf untuk pribadinya. Kesalahan ini misalnya penulisan kata shalat dan zakat dengan huruf waw. Sedangkan hadits "Sesungguhnya al Quran diturunkan dengan tujuh huruf ..." dianggap sebagai hasil rekayasa untuk pembenaran terhadap kekeliruan yang terjadi. Pandangan dan sikap kritis seperti ini dikemukakan antara lain oleh beberapa intelektual dari Jaringan Islam Liberal (Ghazali, 2009: 27).

3. Pendekatan fenomenologis melihat adanya perbedaan dalam bacaan atau penulisan al Quran memang terjadi sejak zaman Nabi. Perbedaan tersebut ternyata memang dibolehkan secara langsung oleh Nabi Muhammad SAW. 
Toleransi tersebut diberikan oleh Beliau dengan mempertimbangkan adanya perbedaan di kalangan umat Islam dalam hal pengetahuan, kemampuan atau bahasa dan perbedaan dialek bahasa Arab di kalangan sahabat itu sendiri. Bagi kalangan fenomenologis ini, kebolehan untuk berbeda dalam membaca al Quran ini menunjukkan tingginya toleransi Nabi dalam menghadapi perbedaan di kalangan umat Islam. Perbedaan dalam hal yang sensitif saja, seperti bacaan dan tulisan al Quran, oleh Beliau masih diberi kelonggaran, apalagi perbedaan dalam persoalan kecil lainnya yang tentu lebih dibolehkan. Pendekatan fenomenologis ini lebih tepat untuk menciptakan hubungan serasi dan harmonis di tengah berbagai perbedaan. Hal lebih penting lainnya adalah kemampuan pandangan fenomenologis ini dalam menciptakan kebebasan dan mendorong umat Islam untuk tetap kreatif dan inovatif dalam membangun peradaban, sebagaimana dicontohkan oleh keragaman banyak sahabat dalam menulis mushaf, dan sikap Nabi SAW yang tetap mengakomodir berbagai perbedaan tersebut.

\section{Simpulan}

Penyatuan mushaf Utsmani mulai terjadi pada tahun $25 \mathrm{H}$, pada tahun ke 2 atau ke 3 dari kekhilafahan Utsman, hasilnya menjadi acuan satu-satunya bagi seluruh umat Islam. Mushaf standar ini dinamakan Mushaf Utsmani atau Mushaf al Imam. Usaha Ustaman yang sungguh-sungguh tampak berhasil dalam mengkodifikasikan al Quran. Pertama, tidak ada mushaf profinsi Muslim kecuali Mushaf utsmani yang telah menyerap kedarah daging mereka. Kedua, kerangka teks Mushafnya dalam jangka waktu empat belas abad tidak bisa dirusak. Sampai hari ini terdapat banyak mushaf yang dinisbatkan langsung kepada Utsman, artinya bahwa mushaf-mushaf asli tersebut asli atau kopian resmi dari yang asli. Inda Office Library (London), dan Tashkent (dikenal dengan Mushaf Samarkand), mushaf-mushaf ini ditulis pada kulit bukan pada kertas dan tampak sejaman, teks-teksnya cocok satu sama lain dan sama dengan mushaf-mushaf dari abad pertama hijriyah dan setelahnya, sampai pada Mushaf yang digunakan saat ini. Meskipun tetap merupakan salah satu kekayaan tertulis yang agung di dunia, sayang sekali Mushaf Samarqand ini tidak lagi murni. Keterikatan kaum orientalis pada mushaf ini begitu menggebu-gebu, sehingga S. Pissareff pada tahun 1905 berikhtiar untuk menerbitkan edisi faksimil. Sebelum melakukan itu ia menebali tulisan-tulisan 
yang telah kabur karena masa pada lembaran-lembaran itu dengan tinta baru, sebagai proses memperkenalkan perubahan-perubahan yang terjadi pada teks. Perubahan yang dilakukan beberapa kali pada Mushaf untuk menyebarkannya di kalangan masyarakat, tidak mempengaruhi pembaca dan arti ayat.

\section{Daftar Pustaka}

Adnan, Amal Taufiq. 2001. Rekontruksi Sejarah al Quran.Yogyakarta: Forum Kajian Budaya dan Agama.

Al Bukhari, Muhammad ibn Ismail.tt. Sahih al Bukhari juz VI, Bandung: PT. Al Maarif

Al Suyuthi. 1978. al Itqan fi 'Ulum al Quran. Mesir: Dar al Fikr al' Arabi

Al A'zami, MM. 2005. The History of The Quranic Text From Revelation To Compilation. Jakarta: Gema Insani.

Denver, Ahmad Van. Ted. 1988. Ilmu al Quran, Pengenalan Dasar. Terjemahan oleh Budiman. Jakarta: Rajawali Press.

Ghazali, Abdul Moqsith.2009. Metodology Studi al Quran. Jakarta: PT Gramedia

Said, Sukamto. 2008. Inzal al Quran 'ala Sab'ah Ahruf wa Mafhumuh min al Manzhur al Ijtima'i wal Lughawi. Al Jami’ah. Edisi 2. 